\title{
Role of Nerve Growth Factor in Assessing the Severity of Clinical Manifestations and Outcomes of Perinatal CNS Lesions in Infants
}

\author{
Olga N. Krasnorutskaya, PhD*; Daniel Yu. Bugrimov, PhD; \\ Anna A. Zuykova, PhD, ScD; Alexander N. Pashkov, PhD, ScD; \\ Julia A. Kotova, PhD; Natalia V. Strakhova, PhD; Irina S. Dobrynina, PhD \\ Voronezh State Medical University named after N.N. Burdenko \\ Voronezh, the Russian Federation
}

\begin{abstract}
The purpose of our research was to analyze the association between the serum beta-NGF level and the severity of neurological deficit (ND) in children in the first year of life. Our results suggest a possible functional link between the low level of NGF and the development of severe ND. The obtained results allow us to consider the serum beta-NGF level as a useful marker of the ND severity in young children.(Int J Biomed. 2016; 6(4):276-278.)
\end{abstract}

Key words: nerve growth factor $\bullet$ neurological deficit $\bullet$ central nervous system $\bullet$ perinatal lesions.

\section{Introduction}

Despite the current improvement in perinatal care, a high incidence of perinatal lesions of the central nervous system (CNS) still persists. ${ }^{[1]}$ Perinatal hypoxia is a common complication of pregnancy and childbirth, an important cause of central nervous system damage in newborns, leading to serious long-term neurological complications. Neurological deficit (ND), as a consequence of perinatal damage, ranges from mild behavioral disorders to cerebral palsy, epilepsy, mental retardation, etc. ${ }^{[2]}$ In addition to the evaluation of the functional activity of nerve cells, an assessment of their trophic supply with the participation of neurotrophins (NTs) is very important. ${ }^{[3]}$ Several neurotrophins have a multifunctional role both in the central and peripheral nervous system. ${ }^{[4]}$ These neurotrophic factors are important regulators of neuronal development, proliferation, differentiation and maturation of the peripheral and central nervous system. ${ }^{[5]}$ Experimental animal models showed that these neurotrophins could be effective in restoring neuronal cells after brain ischemia, ${ }^{[6]}$ suggesting that they might be used as therapeutic agents for treating this kind of brain damage. ${ }^{[4]}$

*Corresponding author: Olga N. Krasnorutskaya, PhD. Voronezh State Medical University named after N.N. Burdenko. Voronezh, Russia. E-mail: onkrasnorutckaja@rambler.ru
NGF (nerve growth factor) is most interesting among NTs as a marker of neurologic deficit (ND). NGF is widely expressed in various tissues; it may have a neurotrophic effect on damaged neurons and promote neurogenesis. ${ }^{[7]}$ NGF supports the survival and differentiation of neurons during brain development. ${ }^{[8]}$ It has been shown that NGF reduces neural degeneration ${ }^{[9]}$ and promotes peripheral nerve regeneration in rats. ${ }^{[10]}$ It appears globally neuroprotective to the developing brain in a neonatal model of cerebral hypoxia-ischemia ${ }^{[11]} \mathrm{A}$ certain NGF level in the blood is an indication of the normal function of glial cells. ${ }^{[12]}$ Exogenous administration of NGF and other NTs has been shown to prevent or significantly reduce severe ND, apoptosis, and brain-cell death. ${ }^{[13-16]}$ The mechanisms underlying this neuroprotective role of NGF are not fully characterized, but several studies have shown its positive influence on cerebral blood flow, cellular $\mathrm{Ca} 2+$ homeostasis, and antioxidant activity. ${ }^{[13,14,17-19]}$

The purpose of our research was to analyze the association between the serum beta-NGF level and the severity of ND in children in the first year of life.

\section{Material and Methods}

The study included 419 patients (52\% boys and $48 \%$ girls) aged from 0 to 6 months. The main group (Group 1) included 336 patients in the first year of life who were 
hospitalized with perinatal nervous system lesions of varying severity; the control group included 83 apparently healthy children. Children in the control group (Group 2) passed standard clinical examinations in specified periods of observation at the stage of outpatient services.

Groups 1 and 2 were divided into two subgroups according to age: Group 1a $(\mathrm{n}=163)$ and Group 2a $(\mathrm{n}=43)$ between the ages of 1 to 3 months; Group $1 \mathrm{~b}(\mathrm{n}=173)$ and Group $2 \mathrm{~b}(\mathrm{n}=40)$ between the ages of 4 to 6 months. In accordance with the ND severity, the main group was also divided into subgroups: mild degree $(\mathrm{n}=122)$, moderate degree $(\mathrm{n}=118)$, and severe degree $(\mathrm{n}=96)$.

All of children underwent the somatic and neurological examination. To assess the damage to the nervous system, YA Yakunin's classification (1979) was used. ND was evaluated by a quantitative method based on the 3 points according to the severity $(0$ - norm, 1 - mild ND, 2 - moderate ND, and 3 - severe ND).

The serum level of the beta subunit of human NGF (betaNGF) was measured by EIA (Beta-NGF, «RayBio» Russia.). The test was conducted according to the standard guidelines suggested by the manufacturer. Sensitivity was $1 \mathrm{pg} / \mathrm{mL}$ and cross-reactivity with other neurotrophic factors was less than $0.3 \%$. All assays were performed in triplicate and results were expressed as $\mathrm{pg} / \mathrm{mL}$.

Statistical analysis was performed using StatSoft Statistica v6.0. Baseline characteristics were summarized as frequencies and percentages for categorical variables and as mean \pm SD for continuous variables. Pearson's Correlation Coefficient ( $r$ ) was used to determine the strength of the relationship between the two continuous variables. Multiple comparisons were performed with one-way ANOVA and post-hoc Tukey HSD test. A probability value of $P<0.05$ was considered statistically significant.

\section{Results and Discussion}

Analyzing the frequency of clinical neurological manifestations in the main group, we found that the dominant neurological syndromes were intracranial hypertension syndrome (91\%), two-sided pyramidal insufficiency (89\%), vegetative-visceral dysregulation (54\%), movement disorders
$(43 \%)$, various paroxysmal states $(17 \%)$ and liquorodynamic disorders, (28\%), and organic lesions of CNS (21\%).

The structure of the ND severity was as the following:

- Group 1a: mild degree of clinical manifestations was detected in 60(36.8\%) children, moderate degree in 58(35.6\%) children, and severe degree in $45(27.6 \%)$ children.

- Group 1b: mild degree of clinical manifestations was detected in 62(35.8\%) children, a moderate degree in $60(34.7 \%)$ children, and a severe degree in 51(29.5\%) children.

- Control group: In each age subgroup, reference values for the studied parameters were determined using the accumulated average; the obtained values for two subgroups coincided with each other, and the baseline values for comparison in this regard were identified as common.

The correlation analysis showed the presence of significant high direct links between the low level of NGF and the clinical condition of the child in all groups: Graefe's symptom $(\mathrm{r}=0.67, P<0.05)$, decrease in muscle tone $(\mathrm{r}=0,84$, $P<0.05)$, reduction of tendon reflexes $(\mathrm{r}=0.77, P<0.05)$, asymmetry of folds $(\mathrm{r}=0.83, \mathrm{P}<0.05)$, the presence of pyramidal signs $(\mathrm{r}=0.89, P<0.05)$.

In the control group, the serum level of beta-NGF was the same for Group 2a and Group 2b $(243 \pm 168.62 \mathrm{pg} / \mathrm{ml})$. Thus, we found no age-related effect on the beta-NGF levels.

In the Group 1a subgroup with the mild clinical manifestations of ND, the average beta-NGF level significantly increased compared to the control group. In Group 1 a subgroup with the moderate and severe clinical manifestations of ND, the serum level of beta-NGF significantly decreased by $17 \%$ and $31 \%$, respectively (Table 1).

In the Group $1 \mathrm{~b}$ subgroup with the mild clinical manifestations of ND, the average beta-NGF level was also significantly increased compared to the control group. In the Group 1b subgroup with the moderate and severe clinical manifestations of ND, the serum level of beta-NGF significantly decreased by $21.5 \%$ and $40 \%$, respectively (Table 1).

ANOVA showed a main effect of the ND severity $(P<0.000)$ in both age groups. In fact, post-hoc comparisons between groups revealed a decrease in the beta-NGF levels with the severity of ND.

\section{Table 1.}

The serum level of beta-NGF $(\mathrm{pg} / \mathrm{ml})$ in the studied groups

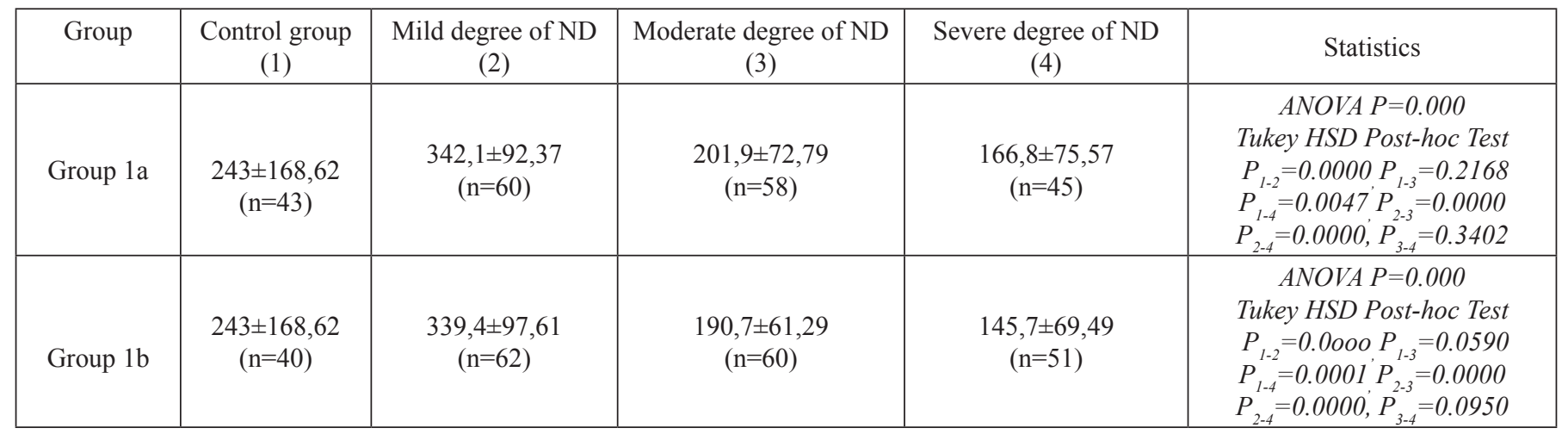


These results reflect the association between beta-NGF level and the ND severity.

Previous experimental and clinical studies have shown that hypoxic-ischemic brain injury (HIBI) determines an increased expression of NGF and other neurotrophic factors in CNS. The increased expression of NGF in HIBI patients plays a key role in response after injury, and may have a beneficial impact on the regenerative capacity of the injured tissues ${ }^{[20]}$ that we observed in mild degree of ND. Our results suggest a possible functional link between the low level of NGF and the development of severe ND. Indeed, both in animal models and in humans, a low level of circulating NGF is associated with sensory and/or sympathetic neuronal deficits and even cell death. ${ }^{[21]}$

Thus, the obtained results allow us to consider the serum beta-NGF level as a useful marker of the ND severity in young children and open up new possibilities for the pathogenetic choice of drug therapy and evaluation of its effectiveness.

\section{Competing interests}

The authors declare that they have no conflict of interest.

\section{References}

1. Balakireva EA, Krasnorutskaya ON, Kalmikova GV. Unresolved issues of child neurology. Belgorod State University Scientific Bulletin: Medicine\&Pharmacy. 2014; 28(24$1 ; 195): 5-7$.

2. Balakirev EA, Krasnorutskaya ON, Zuykova AA. Assessment of the participation of biochemical markers of perinatal lesions of the central nervous system in infants. Journal of New Medical Technologies. 2014; 21(2):26-9.

3. Krasnorutskaya ON, Balakirev EA, AA Zuykova. The predictive model for the level of participation of markers of perinatal lesions of the central nervous system in infants. Proceedings of the International scientific-practical conference "The modern view on the future of science". SC «Aeterna»; 2014:84-88.

4. Lykissas MG, Batistatou AK, Charalabopoulos KA, Beris AE. The role of neurotrophins in axonal growth, guidance, and regeneration. Curr. Neurovasc Res. 2007;4(2):143-51.

5. Han BH, Holtzman DM. BDNF protects the neonatal brain from hypoxic-ischemic injury in vivo via the ERK pathway. J Neurosci. 2000; 20:5775-81.

6. Wang Y, Chang CF, Morales M, Chiang YH, Hoffer J. Protective effects of glial cell line-derived neurotrophic factor in ischemic brain injury. Ann NY Acad Sci. 2002; 962:423-37. 7. Krasnorutskaya ON, Balakireva EA, Bugrimov DYu, Zuykova AA, Dobrynina IS. Neuro-biochemical parameters in the assessment of the effects of perinatal lesions of the nervous system in young children and their prognostic significance.
Science Almanac. 2015;4 (6):237-42.

8. Barde, Y.A. Neurotrophins: A family of proteins supporting the survival of neurons. Prog Clin Biol Res. 1994; 390:1855-9.

9. Tuszynski M, BleschA. Nerve growth factor: From animal models of cholinergic neuronal degeneration to gene therapy in Alzheimer's disease. Prog Brain Res. 2004; 146:441-9.

10. Sun W, Sun C, Lin H, Zhao H, Wang J, Ma H, et al. The effect of collagen-binding NGF-beta on the promotion of sciatic nerve regeneration in a rat sciatic nerve crush injury model. Biomaterials. 2009; 30:4649-55.

11. Holtzman DM, Sheldon RA, Jaffe W, Cheng Y, Ferriero DM. Nerve growth factor protects the neonatal brain against hypoxic-ischemic injury. Ann Neurol. 1996; 39:114-22.

12. Sokolova $\mathrm{MG}$ The value of brain-derived neurotrophic factor (BDNF) (BDNF) and the nerve growth factor (NGF) in adolescents with residual-organic disorders of CNS of perinatal origin. Modern medicine: current issues. 2014; 32:42-9.

13. Calza L, Giuliani A, Fernandez M, Pirondi S, D’Intino $\mathrm{G}$, Aloe L, et al. Neural stem cells and cholinergic neurons: regulation by immunolesion and treatment with mitogens, retinoic acid, and nerve growth factor. Proc Natl Acad Sci USA. 2003; 100:7325-30.

14. Cheng B, Mattson MP. NT-3 and BDNF protect CNS neurons against metabolic/excitotoxic insults. Brain Res. 1994; 640:56-67.

15. Kim BT, Rao VL, Sailor KA, Bowen KK, Dempsey RJ. Protective effects of glial cell line-derived neurotrophic factor on hippocampal neurons after traumatic brain injury in rats. $\mathrm{J}$ Neurosurg. 2001; 95:674-9.

16. Sinson G, Perri BR, Trojanowski JQ, Flamm ES, McIntosh TK. Improvement of cognitive deficits and decreased cholinergic neuronal cell loss and apoptotic cell death following neurotrophin infusion after experimental traumatic brain injury. J Neurosurg. 1997; 86:511-8.

17. Chiaretti A, Antonelli A, Riccardi R, Genovese O, Pezzotti P, Di Rocco C, et al. Nerve growth factor expression correlates with severity and outcome of traumatic brain injury in children. Eur J Paediatr Neurol. 2008;12(3):195-204.

18. Sofroniew MV, Howe CL, Mobley WC. Nerve growth factor signaling, neuroprotection, and neural repair. Annu Rev Neurosci. 2001; 24:1217-81.

19. Zhou Z, Chen H, Zhang K, Yang H, Liu J, Huang Q. Protective effect of nerve growth factor on neurons after traumatic brain injury. J Basic Clin Physiol Pharmacol. 2003; $14: 217-24$.

20. Lindvall O, Kokaia Z, Bengzon J, Elmer E, Kokaia M. Neurotrophins and brain insults. Trends Neurosci. 1994; 17 : 490-96.

21. De Santis S, Pace A, Bove L, Cognetti F, Properzi F, Fiore $\mathrm{M}$, et al. Patients treated with antitumor drugs displaying neurological deficits are characterized by a low circulating level of nerve growth factor. Clin Cancer Res. 2000;6(1):90-5. 